\title{
A Recurrent Neural Network for Warpage Prediction in Injection Molding
}

\author{
A. Alvarado-Iniesta ${ }^{1}$, D.J. Valles-Rosales ${ }^{2}$, J.L. García-Alcaraz ${ }^{1}$, A. Maldonado-Macias ${ }^{1}$ \\ ${ }^{1}$ Departamento de Ingeniería Industrial y Manufactura \\ Universidad Autónoma de Ciudad Juárez \\ Ciudad Juárez, Chihuahua, México \\ *alejandro.alvarado@uacj.mx \\ ${ }^{2}$ Department of Industrial Engineering \\ New Mexico State University \\ Las Cruces, NM, USA
}

\begin{abstract}
Injection molding is classified as one of the most flexible and economical manufacturing processes with high volume of plastic molded parts. Causes of variations in the process are related to the vast number of factors acting during a regular production run, which directly impacts the quality of final products. A common quality trouble in finished products is the presence of warpage. Thus, this study aimed to design a system based on recurrent neural networks to predict warpage defects in products manufactured through injection molding. Five process parameters are employed for being considered to be critical and have a great impact on the warpage of plastic components. This study used the finite element analysis software Moldflow to simulate the injection molding process to collect data in order to train and test the recurrent neural network. Recurrent neural networks were used to understand the dynamics of the process and due to their memorization ability, warpage values might be predicted accurately. Results show the designed network works well in prediction tasks, overcoming those predictions generated by feedforward neural networks.
\end{abstract}

Keywords: Artificial neural network, recurrent neural network, plastic injection molding, warpage prediction.

\section{RESUMEN}

La inyección de plásticos se considera como uno de los procesos de manufactura más flexibles y económicos con un gran volumen de producción de piezas de plástico. Las causas de variación durante la inyección de plásticos se relacionan con el amplio número de factores que intervienen durante un ciclo de producción regular, tales variaciones impactan la calidad del producto final. Un problema común de calidad en productos terminados es la presencia de deformaciones. Así, este estudio tuvo como objetivo diseñar un sistema basado en redes neuronales recurrentes para predecir defectos de deformación en productos fabricados por medio de inyección de plásticos. Se emplean cinco parámetros del proceso por ser considerados críticos y que tienen un gran impacto en la deformación de componentes plásticos. El presente estudio hizo uso del software de análisis finito llamado Moldflow para simular el proceso de inyección de plásticos para recolectar datos con el fin de entrenar y probar la red neuronal recurrente. Redes neuronales recurrentes fueron utilizadas para entender la dinámica del proceso y debido a su capacidad de memorización, los valores de deformación pudieron ser predichos con exactitud. Los resultados muestran que la red diseñada funciona bien en términos de predicción, superando aquellas predicciones generadas por redes de propagación hacia adelante.

\section{Introduction}

Plastic components manufactured through injection molding are frequently used in every single area of the industry such as packaging, building, automotive, aerospace, as well as for medical applications, electrical circuits, among other hundreds of applications. Some of the main issues involved in the injection molding process are the reduction of cycle time, lower production cost, and quality improvement of molded parts [1]. Causes of variations in injection molding are related to the complexity of the process itself. This complexity is generally caused for the vast number of factors acting during a regular production run, which directly impacts the quality of final products. During the injection molding process, residual stresses are produced because of the temperature 
changes, high pressures, and relaxation of the polymer chains, resulting in warpage of the molded part. Warpage is considered as one of the most typical defects found in plastic parts, impacting the appearance and usage of the finished product. Therefore, injection molding companies are interested on determining when a defect such as warpage might be present on their finished products. Hence, if defects are detected before they show, injection molding companies will see a great impact on their expected profit.

Various approaches show improvements on overcoming the complexity of the injection molding process, manipulation of process parameters, and prediction of common quality defects such as warpage, specifically using artificial neural networks. For instance, $\mathrm{He}$ and Huang [2] introduced a predicting model for the waterassisted injection molding process based on artificial neural networks. This approach consisted of predicting the desired processing parameters when desired wall thicknesses are tested. Liao and Hsieh [3] implemented an artificial neural network for predicting shrinkage and warpage of molded thin-wall parts. Chen et al. [4] developed a neural network for quality prediction in injection molding, specifically part weight, by using self-organizing maps and feedforward networks along with Taguchi's parameter design method to improve performance of the network. Lau et al. [5] presented a new methodology to predict part weight and optimize the process parameters to minimize variations in the part weight. Radial basis neural networks, support vector machine, and virtual search method are the techniques used in the paper. Li et al. [6] proposed a system based on neural networks, fuzzy logic, and genetic algorithms for part weight prediction. Reddy et al. [7] developed a warpage prediction model using injection molding process modeling and artificial neural networks. Shi et al. [8] proposed a method for minimizing warpage of molded parts by using artificial neural networks and process simulations. Yin et al. [9] presented an approach to predict warpage in finished products through feedforward neural networks.

All the papers cited above accomplished their objective of optimizing and predicting parameters or desired responses in the injection molding process. There are all kinds of different techniques employed as well as procedures; however, all the papers mentioned beforehand use feedforward neural networks. Therefore, recurrent neural networks (RNNs) are an alternative method to be a better prediction technique than feedforward neural networks; recurrent neural networks allow information to be temporally memorized in the network. Goh et al. [10], Quek et al. [11], Kvasnicka et al. [12], Cai et al. [13], Lu and Tsai [14], Costa and Ribeiro [15], and Lu et al.[16] show the use of recurrent neural networks for prediction in several different applications but not in the prediction of quality defects in injection molding.

This study aims to design a prediction scheme based on recurrent neural networks to predict warpage values of molded components in injection molding. Five process parameters are employed for being considered to be critical process parameters that have great impact on the warpage of molded parts [17-21]. Hence, melt temperature, mold temperature, packing pressure, packing time, and cooling time are used as key variables of the injection molding process. Latter, it is simulated by Autodesk Moldflow Insight 2011. In this study, a recurrent neural network with two hidden layers is assessed. Two hidden layers are employed to ensure feedback connections have an impact on the behavior of the network. Using this type of architecture, it is assumed that the network may be adjusted in all its layers. The following section presents the theoretical background behind injection molding and artificial neural networks specifically recurrent neural networks. Then, Section 3 presents the methodology used in this study. Finally, Section 4 presents the results obtained and some conclusions derived from the study.

\section{Theoretical background}

Injection molding is classified as one of the most flexible and economical manufacturing processes with high volume of plastic molded parts. The injection molding process is a quite complicated process that can be described as follows: plastic material (a polymer that exhibits plasticizing) is heated and melted; this melt is injected into a mold via pressure until the mold cavity is completely filled; then, the part cools and solidifies, duplicating the mold cavity. Once the part solidifies, the mold opens and the part is ejected; meanwhile, the next shot is being prepared, then the mold closes, and 
the cycle begins one more time [1]. Certainly, the process seems to be straightforward; however, each plastic behaves differently when is subjected to heat and pressure. Therefore, changes in melting temperature, injection pressure and other factors must be understood. Injection molding is a challenging process for manufacturers and researchers because they try to produce parts at the lowest cost, reduce cycle time and maintain process under control. If the process is not maintained under control, serious quality problems might occur; increasing manufacturing costs. Production of molded plastic parts requires parts meeting required specifications. Lack of these specifications will result in poor quality of molded parts.

\subsection{Artificial neural networks}

For many years researchers have explored the engineering of the brain. Better understanding of the brain behavior makes a better imitation of it possible. Therefore, new technologies have arisen with the aim of achieving human-like performance such as artificial neural networks [22]. These networks are arranged similarly to biological neural interconnections. Based on training by examples, artificial neural networks are one of the most powerful tools for dealing with nonlinear and uncertain systems. In a recurrent neural network, outputs of some neurons are feedback to the same neuron or feedback to neurons in previous layers [23]. Thus, flow can be in forward and backward directions. Recurrent network architectures have dynamic memory; that is, information is temporally memorized in the network. These networks are intended to learn time-varying patterns and possess arbitrary feedforward and feedback connections; they have nodes which are inputs to other nodes and the feedback to the same node is possible. Feedback nodes memorize previous stages of the hidden units; thus, the new output will depend on the previous stages and a new input. Therefore, feedback connections incorporate short term memory to the network. Figure 1 shows a simple recurrent neural network with a hidden neuron.

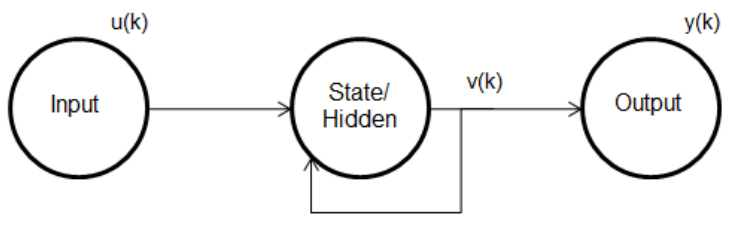

Figure 1. Simple recurrent neural network.
Hence, the output of the network can be expressed by Eq. (1):

$v(k+1)=\sum_{i=0}^{n} w_{u, i}(k) u(k)+\sum_{j=0}^{m} w_{v, j}(k) v(k)(1)$

Where $w_{u, i}$ and $w_{v, j}$ represents the weights related to $u$ and $v$, respectively. Then, the output of the network is generated by Equation (2):

$y(k)=f(v(k))$

Where

$f(v(k))=1 /[1+\exp (-(v(k)))]$

The most common training algorithms for recurrent neural networks are those centered on employing gradient descent algorithms. Mostly, there are two types of gradient descent algorithms: backpropagation through time and recursive backpropagation (also known as real-time recurrent learning). The backpropagation through time algorithm is based on altering the network structure, from a feedback structure to a merely feedforward structure by unfolding the network across time. In this study, backpropagation through time algorithm is used for training the recurrent neural network designed.

\section{Methodology}

The first step in this study was to provide the necessary information to the injection molding process simulator (Moldflow) to obtain numerical cases for training and testing the designed recurrent network. Autodesk Moldflow software was employed in this study to obtain the warpage values of molded parts. Consequently, data obtained from simulations was used to train and test the designed neural network.

\subsection{Process simulation}

Injection molding may be divided into three stages: mold design (part design), material selection, and process itself. First, a specimen to be molded must be established. A specimen typically used for testing new plastic materials was employed in this study; a type $V$ specimen derived from the American Society for Testing and Materials (ASTM) 638. The material used was a polymer 
commonly used in the automotive industry, Zytel 70G35HSLRA4 BK267 which is manufactured by DuPont engineering polymers. Table 1 shows some of the material properties. An Arburg Allrounder $220 \mathrm{~S} 17$ tons $1.3 \mathrm{oz}$. (18mm) injection molding machine was used for the simulation, Table 2 shows the specifications of the selected machine. Table 3 shows the recommended process parameters used for running the simulation. A design of experiments (DOE) was conducted to execute the process simulations; each process parameter (factor) was divided into three levels. Thus, a $3^{5}$ full factorial design was implemented with a total of 243 cases. Table 4 shows the different factors used in this study as well as each level assigned to each factor.

\begin{tabular}{ll}
\hline \hline Family name & POLYAMIDES (NYLONS, PPA, ...) \\
Trade name & Zytel 70G35HSLRA4 BK267 \\
Manufacturer & DuPont Engineering Polymers \\
Family abbreviation & PA66 \\
Material structure & Crystalline \\
Recommended mold temperature & $95{ }^{\circ} \mathrm{C}$ \\
Recommended melt temperature & $295{ }^{\circ} \mathrm{C}$ \\
Recommended ejection temperature & $206{ }^{\circ} \mathrm{C}$ \\
Melt density & $1.223 \mathrm{~g} / \mathrm{cm}^{\wedge} 3$ \\
Solid density & $1.4369 \mathrm{~g} / \mathrm{cm}^{\wedge} 3$ \\
Maximum shear stress & $0.5 \mathrm{MPa}$ \\
Maximum shear rate & $600001 / \mathrm{s}$ \\
Elastic modulus & $9120 \mathrm{MPa}$ \\
Poisson ratio & 0.4 \\
Shear modulus & $2750 \mathrm{MPa}$ \\
Observed nominal shrinkage (parallel, perpendicular) & $0.2102 \%$ and $1.363 \%$, respectively \\
\hline \hline
\end{tabular}

Table 1. Material Properties.

\begin{tabular}{ll}
\hline \hline Trade name & Allrounder 220 S 17 tons 1.3 oz. (18mm) \\
Manufacturer & Arburg \\
Injection unit & \\
Maximum machine injection stroke & $55.58 \mathrm{~mm}$ \\
Maximum machine injection rate & $32 \mathrm{~cm}$ ^3/s \\
Machine screw diameter & $18 \mathrm{~mm}$ \\
Hydraulic unit & \\
Maximum machine injection pressure & $250 \mathrm{MPa}$ \\
Clamping unit & \\
Maximum machine clamp force & 17 ton \\
\hline \hline
\end{tabular}

Table 2. Machine specifications. 


\begin{tabular}{ll}
\hline \hline Mold surface temperature & $95^{\circ} \mathrm{C}$ \\
Melt temperature & $295^{\circ} \mathrm{C}$ \\
Filling control & \\
Ram speed & $100 \mathrm{~mm} / \mathrm{s}$ \\
Starting ram position & $37 \mathrm{~mm}$ \\
Cushion warning limit & $5 \mathrm{~mm}$ \\
Velocity/pressure switch over & $15 \mathrm{~mm}$ \\
Pack/holding control & \\
Packing pressure & $100 \mathrm{MPa}$ \\
Packing time & $2.5 \mathrm{~s}$ \\
Cooling control & \\
Cooling time & $5 \mathrm{~s}$ \\
Coolant temperature & $66^{\circ} \mathrm{C}$ \\
\hline \hline
\end{tabular}

Table 3. Process parameters.

\begin{tabular}{cccccc}
\hline \hline Level & $\begin{array}{c}\text { Experimental factors } \\
\text { Melt }\end{array}$ & $\begin{array}{c}\text { Mold } \\
\text { temperature }{ }^{\circ} \mathrm{C}\end{array}$ & $\begin{array}{c}\text { Packing pressure } \\
\text { temperature }{ }^{\circ} \mathrm{C}\end{array}$ & $\begin{array}{c}\text { Packing time } \\
(\mathrm{MPa})\end{array}$ & $\begin{array}{c}\text { Cooling } \\
\text { time }(\mathrm{s})\end{array}$ \\
1 & 285 & 70 & 80 & 2 & 4.5 \\
2 & 295 & 95 & 100 & 2.5 & 5 \\
3 & 305 & 120 & 120 & 3 & 5.5 \\
\hline \hline
\end{tabular}

Table $4.3^{5}$ full factorial design.

\subsection{Training the network}

The function of the designed network was to predict the warpage of a plastic part during injection molding under a specified combination of process parameters. Before the recurrent neural network could be used to predict the warpage of molded parts, it had to be trained properly. A data set obtained from the process simulations was used for training purposes. The obtained input-output pairs were divided into a training set and a test set, respectively. Data pairs were normalized between the ranges 0.1 and 0.9 for training and testing. Neural networks work better with data that are within a specific range; furthermore, data normalization improves training characteristics. Data normalization was done by $u_{\text {norm }}=\left(0.8 * \frac{\left(u-u_{\min }\right)}{\left(u_{\max }-u_{\min }\right)}\right)+0.1$

Where $u$ is the actual value, $u_{\min }$ is the minimum value of the data set, $u_{\max }$ is the maximum value of the data set, and $u_{\text {norm }}$ is the normalized data set.

A 5-30-30-1 recurrent neural network was employed in this study to ensure that feedback connections have an impact on the behavior of the network; Figure 2 shows a representation of the designed network. Using this type of architecture, it was assumed that the network may be adjusted in all its layers. Backpropagation through time algorithm was used for training the designed network. Furthermore, a 5-30-30-1 feedforward neural network was trained and tested as well, to compare the performance of the recurrent neural network in terms of prediction. 


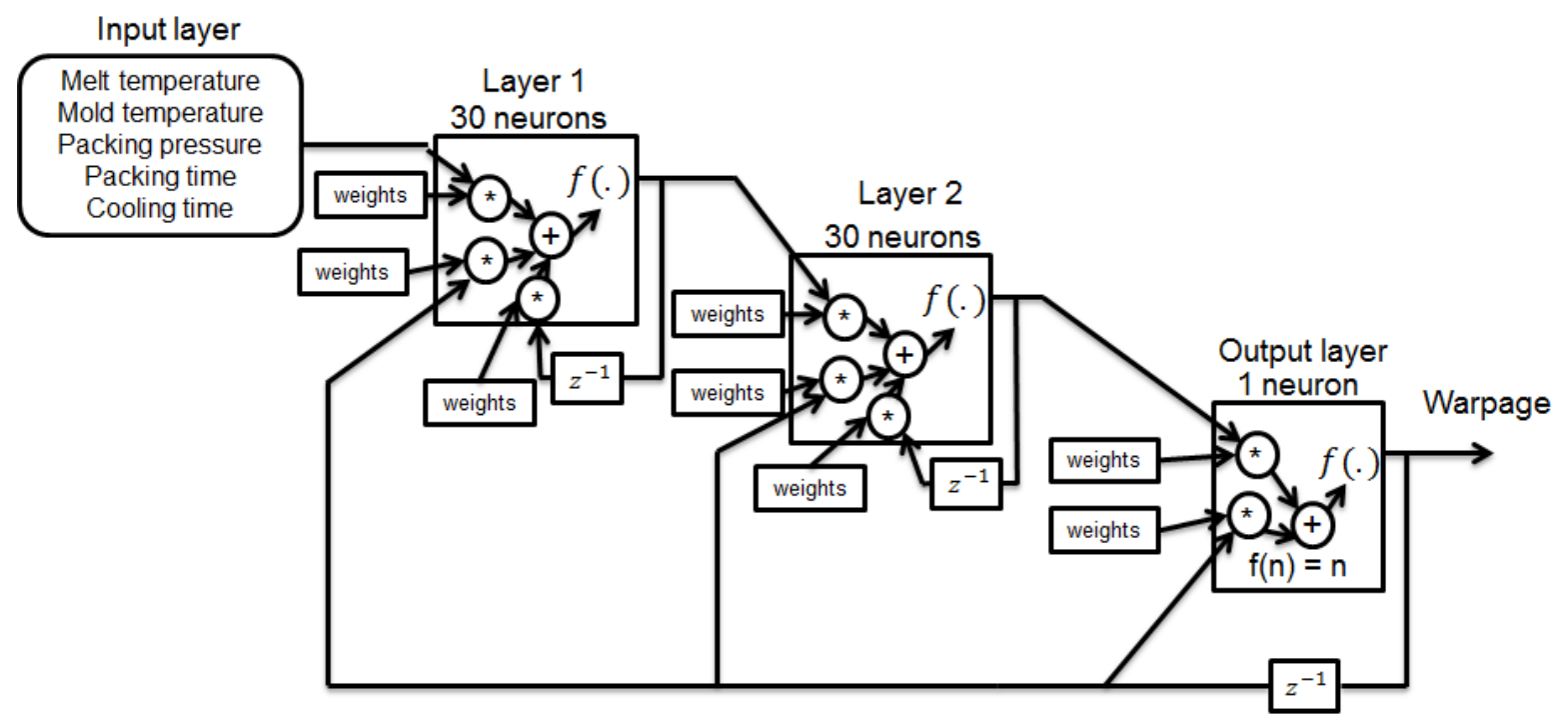

Figure 2. The structure of the designed neural network.

Five critical process parameters were used as inputs to the network, namely melt temperature, mold temperature, packing pressure, packing time, and cooling time. Two hidden layers with 30 hidden neurons on each layer and one output which is the warpage of the molded part were employed. During the training process, learning rate was fixed to 0.01 and momentum to 0.9 . The performance index for training was the mean square error (MSE) and is defined by Equation (5):

$$
M S E=\frac{1}{N} \sum_{k=1}^{l}\left(t_{k}-y_{k}\right)^{2}
$$

where $t_{k}$ is the desired output (target output), $y_{k}$ is the actual output, and $N$ is the number of samples. The same training parameters were used to train both neural networks: feedforward and recurrent. Backpropagation algorithm was employed to train the feedforward neural network.

\subsection{Testing the network}

Once training has been carried out, a test set was presented to the networks to compare their prediction abilities. A data set consisting of 23 different combinations, which were not used in the training stage, were introduced to the networks to be tested. Both networks were tested 30 times to obtain a more reliable estimation of their performance. Thus, a mean value was obtained for each one of the networks to compare their performance in terms of prediction. The procedure to obtain this average included an enormous computational analysis. First, the networks had to be trained and tested during a significant amount of time. The results obtained from the network are then compared to the actual values (measured output).

\subsection{Results}

Results after training showed an average MSE equals to $3.37 \mathrm{e}-24$ for the feedforward network and $2.75 \mathrm{e}-05$ for the recurrent network after 10,000 iterations; the maximum number of iterations was used as termination criteria in both cases. After training and testing both networks thirty times to obtain a more reliable estimation of their performance, the feedforward neural network showed a prediction error of $3.049 \%$ on average while the designed recurrent neural network resulted with a $0.85245 \%$ prediction error on average overcoming the performance of the feedforward network. Figure 3 shows a representation of the average of the predicted values for warpage generated by the recurrent network against the actual values of warpage obtained in Moldflow. From Figure 3, the difference between the actual warpage and the predicted warpage is clearly noticed; the prediction error resulted to be less than $1 \%$ on average. Normal time to run a simulation in Moldflow takes roughly 
300 seconds while the prediction system takes less than 1 second to generate an output. Thus, enhancement in the design and production of new components may be significantly improved by the designed recurrent network.

\section{Conclusions}

This study was intended to develop a new methodology based on recurrent neural networks for warpage prediction of finished products in the injection molding process. In neural networks, there is no rule or algorithm that determines what the best structure is in terms of hidden layers, hidden neurons, or number of feedback connections. Similarly, there are various learning algorithms that can be applied and each one possesses different parameter settings. Results show that the designed recurrent neural network may work well in terms of prediction. In this study, two hidden layers were employed to ensure feedbacks connections have an impact on the behavior of the network. Using this type of architecture, it was assumed that the network may be adjusted in all its layers. Besides, a feedforward neural network was also evaluated to compare the performance of the designed recurrent network. Although, the MSE was smaller for the feedforward network, it does not indicate the network learned to generalize to new situations in a better mode. Hence, a recurrent neural network with five inputs, two hidden layers and one output was implemented suitably with a prediction error of $0.85245 \%$ on average. The aim of this study was to propose a new methodology for prediction purposes in injection molding. Ideally, this methodology may be applied to the real dynamic injection molding process where recurrent networks might work better. That is, according with their memorization ability may predict possible quality defects in real time which may be an indicator of possible problems in the process that has not been identified yet. In conclusion, results obtained in this study seem to make the methodology implemented a good technique for prediction tasks. Therefore, the same idea may be applied to any other application where data could be available.

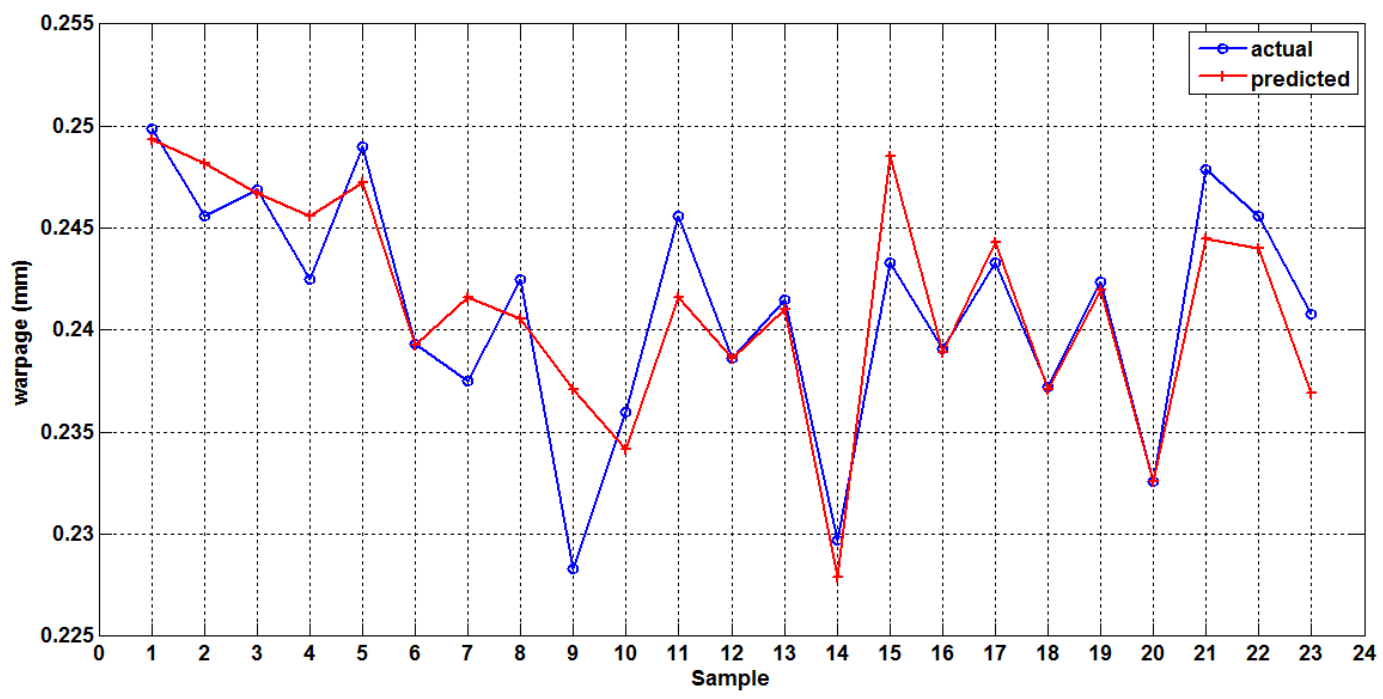

Figure 3. Actual warpage value vs. predicted warpage value. 


\section{References}

[1] D.V. Rosato and D.V. Rosato, "Injection Molding Handbook 2nd ed.", Chapman \& Hall, 1995.

[2] J. He and $\mathrm{H}$. Huang, "Predicting processing parameters for water-assisted injection molding based on inverse GA-LMBP neural network," In Society of Plastics Engineers annual Technical Conference, Cincinnati, OH, 2007.

[3] S. Liao and W. Hsieh, "Shrinkage and warpage prediction of injection-molded thin-wall parts using artificial neural networks," Polym. Eng. Sci., Vol. 44, No. 11, pp. 2029-2040, Nov. 2004.

[4] W. Chen et al., "A neural network-based approach for dynamic quality prediction in a plastic injection molding process," Expert Syst. Appl., Vol. 35, No. 3, pp. 843-849, Oct. 2008.

[5] H. Lau et al., "A new method for monitoring and tuning plastic injection molding machines," Control Intell. Syst., Vol. 36, No. 2, pp. 129-136, Mar. 2008.

[6] E. Li et al., "A Genetic Neural Fuzzy System and its application in quality prediction in the injection process," Chem. Eng. Commun., Vol. 191, No. 3, pp. 335-355, Mar. 2004.

[7] B. Reddy et al., "Application of Soft Computing for the Prediction of Warpage of Plastic Injection Molded Parts," JESTEC, Vol. 2, No. 1, pp. 56-62, 2009.

[8] H. Shi et al., "Optimization of injection molding process parameters using integrated artificial neural network model and expected improvement function method," Int. J. Adv. Manuf. Technol., Vol. 48, No. 9-12, pp. 955-962, 2009.

[9] F. Yin et al., "Backpropagation neural network modeling for warpage prediction and optimization of plastic products during injection molding," Mater. Des., Vol. 32, No. 4, pp. 1844-1850, Apr. 2011.

[10] W. Goh et al., "Application of a recurrent neural network to prediction of drug dissolution profiles," Neural Comput. Appl., Vol. 10, No. 4, pp. 311-317, 2002.

[11] G. Quek et al., "A novel recurrent neural network based prediction system for trading," In International Joint Conference on Neural Networks, Vancouver, Canada, 2006.
[12] V. Kvasnicka et al., "Application of recurrent neural networks in Chemistry: Prediction and classification of 13C NMR Chemical shifts in a series of monosubstituted Benzenes," J. Chem. Inf. Comput. Sci., Vol. 32, No. 6, pp. 742-747, Nov. 1992.

[13] X. Cai et al., "Time series prediction with recurrent neural networks using a hybrid PSO-EA algorithm," IEEE, Vol. 2, pp. 1647-1652, Jul. 2004.

[14] C. Lu and C. Tsai, "Adaptive Predictive Control with Recurrent Neural Network for industrial processes: an application to temperature control of a variablefrequency oil-cooling machine," IEEE Transactions on Industrial Electronics, Vol. 55, No. 3, pp. 1366-1375, Mar. 2008.

[15] N. Costa and B. Ribeiro, "A Neural Prediction model for monitoring and fault diagnosis of a plastic injection molding process", 1999.

[16] C. Lu et al., "Predictive Control Based on Recurrent Neural Network and Application to Plastic Injection Molding Processes," In The 33rd Annual Conference of the IEEE Industrial Electronics Society, Taipei, Taiwan, 2007.

[17] M.C. Huang and C.C. Tai, "The effective factors in the warpage problem of an injection molded part with a thin shell feature," J. Mater. Process. Technol., Vol. 110, No. 1, pp. 1-9, Mar. 2001.

[18] T. Erzurumlu and B. Ozcelik, "Minimization of warpage and sink index in injection-molded thermoplastic parts using Taguchi optimization method," Mater. Des., Vol. 27, No. 10, pp. 853-861, 2006.

[19] B. Ozcelik and I. Sonta, "Warpage and structural analysis of thin shell plastic in the plastic injection molding," Mater. Des., Vol. 30, No. 2, pp. 367-375, 2009.

[20] Y.M. Deng et al., "A hybrid of mode-pursuing sampling method and genetic algorithm for minimization of injection molding warpage," Mater. Des., Vol. 31, No. 4, pp. 2118-2123, Apr. 2010.

[21] B. Farshi et al., "Optimization of injection molding process parameters using sequential simplex algorithm," Mater. Des., Vol. 32, No. 1, pp. 414-423, Jan. 2011.

[22] D. Mandic and J. Chambers, "Fundamentals In Recurrent Neural Networks for Prediction: Learning algorithms, architectures and stability", Wiley, 2001.

[23] D. Pham and L. Xing, "Neural Networks for Identification, Prediction and Control”, Springer, 1995. 